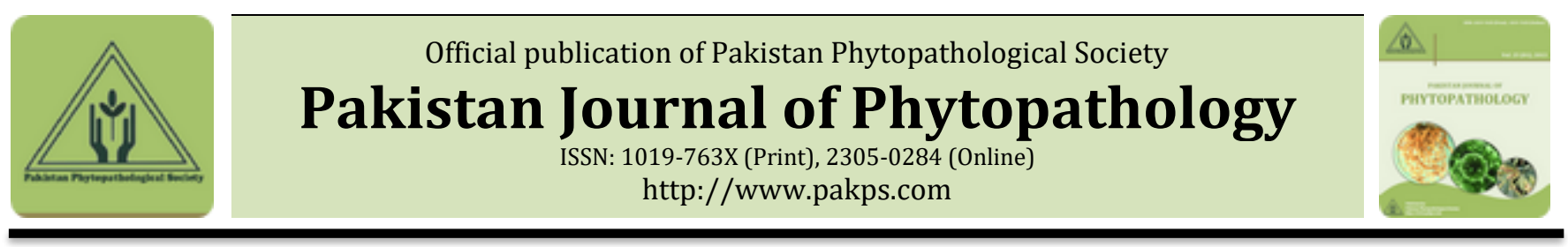

\title{
EFFECT OF SOIL NUTRIENT AND BIOTA DYNAMICS ON WILT DISEASE SEVERITY IN CHICKPEA
}

\author{
a,bDahou Moutassem*, bLakhdar Belabid, aYuva Bellik, cNoureddine Rouag, aSiham Ziouche, aFaiza Baali \\ aLaboratory of Characterization and Valorization of Natural Resources (L.C.V.R.N), Faculty of Nature and Life Sciences, \\ University of Bordj Bou Arreridj, 34000, Algeria. \\ ${ }^{b}$ Laboratory for Research on Biological Systems and Geomatics, Faculty of Nature and Life Sciences, University of Mustapha \\ Stamboli Mascara, 29000, Algeria. \\ ‘Department of Agronomy, Faculty of Nature and Life Sciences, University of Ferhat Abbas Sétif 1, Sétif, 19000, Algeria.
}

\section{A B S T R A C T}

The present study was performed to investigate dynamic and combined effects of soil nutrients (nitrogen and phosphorus) and biotic factors on disease severity of Fusarium wilt in chickpea (AUDPC). Chickpeas were harvested, 180 days after onset of experiment, from eight natural infested soils during two years (2016 and 2017) and assessed for rhizospheric nitrogen (N-Total $\mathrm{R}$ ) and phosphorus availability (Olsen-P) in relation to Fusarium oxysporum f.sp ciceris inoculum density (ID-Foc), Trichoderma spp, and Pseudomonas spp as well as nitrogen (N-Total $\mathrm{PL}_{\mathrm{L}}$ ) and phosphorus (P-TotalPL) plants uptake. The results showed that high level of ID-Foc significantly increased AUDPC values. It was found that ID-Foc was negatively correlated with Olsen-P and positively correlated with N-Total . Accordingly, AUDPC values were positively correlated with high concentrations of $\mathrm{N}-\mathrm{Total}_{\mathrm{R}}\left(r=0.77^{* *}\right.$ in 2016, $r=0.94^{* * *}$ in 2017) while negatively correlated with high concentrations of Olsen-P $\left(r=-0.73^{* *}\right.$ in $2016, r=-0.79^{* *}$ in 2017). In addition, AUDPC values showed negative interactions with $\mathrm{N}$-TotalpL $\left(r=-0.80^{* *}\right.$ in $2016, r=-0.78^{* *}$ in 2017), whereas positive interactions with P-Total $\mathrm{PL}\left(r=0.80^{* *}\right.$ in 2016, $r=0.87^{* *}$ in 2017). Moreover, AUDPC values were negatively associated with Pseudomonas spp and nodosity during the two years of study as with Trichoderma spp in 2017. The results demonstrated that wilt disease severity was strongly associated with nutrients and biological soil properties. It can be assumed that soils with highest Olsen-P levels, Trichoderma spp and Pseudomonas spp can help Fusarium wilt suppression.

Keywords: Chickpea; Fusarium oxysporum f.sp ciceris; Trichoderma spp; Pseudomonas spp; Phosphorus; Nitrogen.

\section{INTRODUCTION}

Fusarium wilt, caused by soil-borne fungus Fusarium oxysporum f. sp. ciceris (Foc), appears to be the most devastating diseases of chickpea throughout the world, particularly, in North Africa (Reddy et al., 1980). The yield losses caused by this soilborne fungus have been estimated to 10 and $15 \%$ worldwide. Total losses may be increased by severe wilt epidemics under some environmental conditions (Navas-Cortes et al., 2000).

Submitted: September 19, 2018

Revised: October 25, 2018

Accepted for Publication: November 29, 2018

* Corresponding Author:

Email: moutassemdahou@gmail.com

(C) 2017 Pak. J. Phytopathol. All rights reserved.
Infection of susceptible host is also possible when survival chlamydospores grown in soil or embedded in plant tissue. This primary inoculum of Fusarium wilt in chickpea can survive on crop residues for more than 6 years in the absence of susceptible host (Haware et al., 1990; Jimenez-Díaz et al., 2015).

Soil is a fundamental medium for crop growth in all production systems. The productivity of any system depends, to a large extent, on soil characteristics such as nutrients supply and structural characteristics that affect rooting (Ghorbani et al., 2008). Soil also hosts a complex fauna and microbial population involved in many different biological processes, which also affects its physical and chemical properties, and ultimately the productivity of agricultural ecosystems. 
Nitrogen and phosphorus are among the main nutrients for plant structure and function $\mathrm{CHu}$ and Schmidhalter, 2005). Nitrogen is a key constituent of proteins and plays an important role in different enzymatic activities of plants, whereas phosphorus is involved in the energy transfer to the cells (ATP and NADPH). It is well established that nitrogen and phosphorus availability can affect the resistance of plants to pathogens (Marschner, 1995). These major constituents ( $\mathrm{N}$ and $\mathrm{P}$ ) afforded important roles in metabolic pathways that lead to the production of lignin, phenols, phytoalexins, and other defenserelated molecules (Elmer and Datnoff, 2014). Despite the fact that $\mathrm{N}$ and $\mathrm{P}$ are among the most vital nutrients for plant, there are many reports demonstrating the effects of $\mathrm{N}$ and $\mathrm{P}$ in the development of plant disease, but still the mechanism of pathogenesis poorly understood (Hoffland et al., 2000). One of the most drawbacks within these studies is that factors (N, P, oligo-elements, etc.) are often evaluated individually on culture medium, making difficult to account the interactions between these nutrients. Therefore, a proper understanding of soil physicochemical and biological characteristics and adequate interpretation of their interactions is required for a better improvement of agricultural productivity. Hence, the main objectives of this study were to evaluate the combined effects of different soil nutrients (N-Total ${ }_{\mathrm{R}}$, Olsen-P) and biotic factors (IDFoc, Trichoderma spp, and Pseudomonas spp) on wilt disease severity in natural soils and controlled conditions during 2 years to predict the effects of the studied variables on the epidemic occurrence of Fusarium wilt.

\section{MATERIALS AND METHODS}

Study sites and soil samples: Eight soil samples were collected from different regions in North Algeria (Skikda, Constantine, M'ila, and Guelma). Each region is represented by two sites. A total of $100 \mathrm{~kg}$ of soil were collected from each site at a depth of 0 to $25 \mathrm{~cm}$ and were stored in closed plastic bags.

Physicochemical and biological analysis of soil: Initial soil samples were air-dried and ground into 2$\mathrm{mm}$ particles for physicochemical and biological analysis. The particle size distribution was studied according to pipette method. The $\mathrm{pH}$ of the different soils was determined in water using a conventional $\mathrm{pH}$ meter $(1 / 2.5, \mathrm{w} / \mathrm{w})$. Calcareous content $\left(\mathrm{CaCO}_{3}\right)$ was assessed using the Bernard calcimeter method. Total nitrogen (N-Total) was assessed by the Kjeldahl method (Lambert, 1977). Available phosphorus (Olsen-P) was determined by the method of Olsen et al., (1954).

The microbial populations of each soil sample were examined using a serial-dilution method as described previously (Rapilly, 1968). Selective Komada's and rose Bengal culture media were used to isolate Fusarium oxysporum and Trichoderma spp, respectively. Ten grams of soil were suspended in 90 $\mathrm{ml}$ of sterile distilled water and shaken at $200 \mathrm{rpm}$ for $30 \mathrm{~min}$. Successive dilutions of $10^{-2}$ and $10^{-3}$ were made from the initial suspension. Aliquots of $10 \mathrm{ml}$ from each dilution were transferred into $90 \mathrm{ml}$ culture medium. The prepared suspensions were poured into Petri dishes and incubated at $25^{\circ} \mathrm{C}$ in the dark for 5 to 14 days. Analyses were performed by counting the number of colonies per Petri dish. Results were expressed as colony-forming units per gram of dry soil (Cfu g-1 dry soil). Microscopic examination was used to identify Fusarium spp by evaluating the morphology of their spore structures and specific identification keys established by Messiaen and Cassini, (1968). Trichoderma spp colonies were identified based on visual macroscopic and microscopic observations according to Gams and Bissett, (2002).

Regarding Pseudomonas spp isolation, $10 \mathrm{~g}$ of each soil were suspended in $90 \mathrm{ml}$ of sterile distilled water, shaken and heated at $45^{\circ} \mathrm{C}$ for $5 \mathrm{~min}$. Aliquots of $10 \mathrm{ml}$ from each dilution were transferred into $90 \mathrm{ml}$ of cetrimide Pseudomonas spp selective medium. The prepared suspensions were poured into Petri dishes and incubated at $37^{\circ} \mathrm{C}$ for 24 to $48 \mathrm{~h}$. Each colony of Pseudomonas spp was isolated and identified based on morphology and total density per sample (colonyforming units $\mathrm{g}^{-1}$ soil). All experiments were carried out in four replicates.

Experimental set-up, disease assessment, and pathogenicity test: The pot experiment was conducted in four replications during the period of December to May 2016 and 2017 at the greenhouse of El Hammadia, Bordj Bou Arreridj, Algeria (attitude $35.979 \mathrm{~N}$ and longitude $4.7477780 \mathrm{E}$ ).

Chickpea seed cultivars (Ghab 5) were surface sterilized using sodium hypochlorite (2\%) for $3 \mathrm{~min}$, rinsed three times with sterile distilled water and 
germinated ( $10 \mathrm{seed} / \mathrm{disc}$ ) at $25 \pm 3^{\circ} \mathrm{C}$ during 8 days in Petri dishes containing two sterilized filter paper. Chickpea seedlings were carefully transferred into soil samples at the rate of five seeds per pot. Seedlings were grown under greenhouse conditions $\left(25^{\circ} \mathrm{C}\right.$ and $70 \%$ humidity) and irrigated with sterile water as needed. The experiment was achieved 180 days after sowing.

The severity of Fusarium wilt was assessed 8-day intervals after the appearance of symptoms using the technique described by Trapero-Casas and JimenezDiaz, (1985). Disease incidence (DI) was assessed by counting the number of plants showing symptoms. Severity of Fusarium wilt was assessed on a scale of 0 to 4 according to the percentage of foliage with yellowing $(0=0 \%, 1=1$ to $33 \%, 2=34$ to $66 \%, 3=67$ to $100 \%$, and $4=$ dead plant). Incidence symptoms (0 or 1 ) and severity data (rated from 0 to 4 ) were used to calculate disease index intensity (Dis) using the equation Dis $=(I \times S) / 4$. Additionally, for each site, the area under disease progress curve (AUDPC) was estimated by the following formula:

$$
A U D P C=\sum_{i+1}^{n}\left[\left(x_{i}+x_{i+1}\right) / 2\right]\left(t_{i+1}-t_{i}\right)
$$

The pathogenicity tests were performed according to pot screening procedure as described by Nene and Haware, (1980). Briefly, the special forme ciceris was determined by inoculation of a variety of chickpea ILC482, highly susceptible to Fusarium wilt. Inoculum was prepared from a single-spore culture of Fusarium oxysporum. After 20 days of culture at $25{ }^{\circ} \mathrm{C}$, the inoculum was thoroughly mixed in the pots and five seeds of susceptible cultivars were sown in each pot.

Plant harvest and rhizosphere soil sampling: During the harvest period, at the full productive stage, shoots of chickpea were separated from roots at the cotyledon node. Rhizosphere soil which corresponds to the fraction of soil adhering to roots was carefully separated from roots, collected and stored in a refrigerator at $4^{\circ} \mathrm{C}$ for more than three days prior to analysis.

Assessment of Olsen-P, N-Total ${ }_{R}$, ID-Foc, Trichoderma spp and Pseudomonas spp: Nitrogen concentration in rhizosphere (N-Total $\left.{ }_{R}\right)$ was determined by Kjeldahl technique. Soil phosphorus (Olsen-P) availability was assessed as described previously (Olsen et al., 1954). To evaluate the dynamic of rhizospheric soil in terms of fungal and bacterial communities, ID-Foc, Trichoderma spp, and Pseudomonas spp were determined using the technique of Rapilly, (1968), as described above.

Assessment of SWD, Yg, and N-TotalpL and PTotalPL shoots uptake: At maturity stage of plant, grain yield (Yg) was determined in the different studied sites. Yg was determined as dry weight after drying for $48 \mathrm{~h}$ at $70^{\circ} \mathrm{C}$. Nodules per plant were separated from roots, dried $\left(48 \mathrm{~h}\right.$ at $\left.70^{\circ} \mathrm{C}\right)$ and weighed. N-TotalpL was determined by the green malachite method as described by Valizadeh et al., (2003). P-Total $\mathrm{PL}$ was calculated as the amount of total phosphorus taken up by the plant (Betencourt et al., 2012).

\section{STATISTICAL ANALYSIS}

One way analysis of variance (ANOVA) with post-hoc Tukey test was used to evaluate differences between soil samples. Significant difference was determined by Tukey's multiple comparison tests at $\mathrm{P}<0.05$. Soil physicochemical and biological properties and AUDPC of Fusarium wilt were also calculated using the Pearson correlations. Statistical analyses were done using the software package STATISTICA 8.

\section{RESULTS}

Soil physicochemical and biological characteristics: Physico-chemical and biological characteristics of the eight experimental sites were given in Table 1. Physical parameters in terms of sand, loam and clay proportion showed highly significant differences between the different sites $(\mathrm{P}<0.001)$. Particle size distribution varied significantly among the studied sites. The highest values of clay (36.02\%), loam $(64.37 \%)$ and sand $(13.63 \%)$ were recorded in S6, S8, and S4, respectively. In contrast, S7 was characterized by a lowest value of clay $(23.49 \%)$ and loam $(53.82 \%)$, while S5 showed the lowest value of sand $(9.37 \%)$.

Statistical analysis showed highly significant differences in soil $\mathrm{pH}, \mathrm{CE}, \mathrm{CaCO}_{3}$ content, Olsen-P and $\mathrm{N}$-total $(\mathrm{P}<0.001)$. In general, $\mathrm{CaCO}_{3}$ ranged from 5.37 to $25.95 \%$ as a result most of the studied soils were calcareous. pH ranged from 7.05 to 8.3 in the different sites. Soil organic matter content ranged from $1.17 \%$ to $1.73 \%$, with highest values in S2 and S6. N-Total was rated as low to medium with values ranging from 0.82 to $1.46 \mathrm{~g} \mathrm{~kg}^{-1}$. P-Total varied between 177.15 and $251.8 \mathrm{mg} \mathrm{kg}^{-1}$ in S4 and S7, respectively. Olsen-P 
showed a large variation among the studied sites, the values increased from 18.6 to $25.08 \mathrm{mg} \mathrm{Kg}^{-1}$. Olsen-P was lowest in $\mathrm{S} 4$ and showed higher value in S7.

Statistical analysis showed that Trichoderma spp., ID-Foc and Pseudomonas spp were significantly affected by site locality $(\mathrm{P}<0.05)$. ID- Foc varied between $6 \times 10^{3}$ and $28.67 \times 10^{3} \mathrm{Cfu} \mathrm{g}^{-1}$ soil. The highest levels were recorded in S1, S2 and S4. In the present study five species of Trichoderma spp were identified; $T$. viride, $T$. harzianum, $T$. atroviride, T. virens, T. polysporum. The studied soils showed that Trichoderma spp ranged between $5 \times 10^{3}$ to $26.33 \times 10^{3} \mathrm{Cfu} \mathrm{g}^{-1}$ soil and were primarily concentrated in S7 and S8.

Morphological observations and biochemical tests revealed three species of Pseudomonas spp; $P$. aeruginosa, $P$. luteola, and $P$. fluorescens, ranging between $60.67 \times 10^{9}$ to $228 \times 10^{9} \mathrm{Cfu}^{-1}$ with highest levels in S3, S7, and S8.

Disease assessment and pathogenicity of Fusarium oxysporum: In the present study, we noticed atypical symptoms of the disease, where first partial yellowing begun from the basal parts and progressed to the upper part of the plants. In the case of a very severe disease, we recorded intensive defoliation, weak flowering or broad spread of sterile flowers, fewer pods, small pods or empty pods. However, in the same case, severely affected plants showed early maturation compared to the less affected plants. Longitudinal or transversal sections of the vascular system showed a large discoloration. This phenomenon subsequently leads to the death of plants. Fusarium oxysporum isolates, obtained from wilted plants and soil samples inoculated on susceptible variety ILC 482 , would be the special form ciceris responsible for the vascular wilt of chickpea, observed in the greenhouse experiment.

Table 1. Physicochemical and biological characteristics of the studied sites.

\begin{tabular}{|c|c|c|c|c|c|c|c|c|c|c|c|c|}
\hline & $\begin{array}{l}\text { Clay } \\
(\%) \\
* *\end{array}$ & $\begin{array}{l}\text { Loam } \\
(\%) \\
* * *\end{array}$ & $\begin{array}{l}\text { Sand } \\
(\%) \\
* * *\end{array}$ & $\mathrm{pH}$ & $\begin{array}{l}\mathrm{CaCO}_{3} \\
(\%) \\
* *\end{array}$ & $\begin{array}{l}\text { Organic } \\
\text { matter } \\
(\%) \\
* * *\end{array}$ & $\begin{array}{l}\text { N-Total } \\
\mathrm{g} \mathrm{Kg}^{-1}\end{array}$ & $\begin{array}{l}\text { Olsen-P } \\
\mathrm{mg} \mathrm{Kg}^{-1}\end{array}$ & $\begin{array}{l}\text { P -Total } \\
\left(\mathrm{mg} \mathrm{kg}^{-1}\right) \\
* *\end{array}$ & $\begin{array}{l}\text { ID-Foc } \\
* * \\
\left(10^{3} \mathrm{Cfu} \mathrm{g}^{-1}\right)\end{array}$ & $\begin{array}{l}\text { Trichoderma spp } \\
* * * \\
\left(10^{3} \mathrm{Cfu}^{-1}\right)\end{array}$ & $\begin{array}{l}\text { Pseudomonas spp } \\
* * * \\
\left(10^{9} \mathrm{Cfu} \mathrm{g}^{-1}\right)\end{array}$ \\
\hline S1 & $25.43 \pm 0.08 \mathrm{c}$ & $62.33 \pm 0.13 b$ & $12.25 \pm 0.16 \mathrm{ab}$ & $8.3 \pm 0.00 \mathrm{a}$ & $8.25 \pm 0.28 \mathrm{f}$ & $1.58 \pm 0.12 \mathrm{ab}$ & $1.24 \pm 0.03 \mathrm{bc}$ & $21.06 \pm 0.49 \mathrm{bc}$ & $184.49 \pm 1.58 \mathrm{de}$ & $28.67 \pm 8.65 \mathrm{a}$ & $13.33 \pm 0.88 \mathrm{~cd}$ & $60.67 \pm 8.69 \mathrm{~d}$ \\
\hline S2 & $26.71 \pm 0.02 \mathrm{~b}$ & $62.43 \pm 0.85 b$ & $10.86 \pm 0.85 b c$ & $8.02 \pm 0.02 b$ & $5.37 \pm 0.20 \mathrm{~g}$ & $1.69 \pm 0.03 \mathrm{~d}$ & $1.34 \pm 0.02 \mathrm{~b}$ & $19.09 \pm 0.24 \mathrm{~cd}$ & $226.68 \pm 3.19 b$ & $22.33 \pm 1.86 a b$ & $8 \pm 1.73 \mathrm{~cd}$ & $79 \pm 3.46 \mathrm{~cd}$ \\
\hline S3 & $26.32 \pm 0.28 \mathrm{~b}$ & $63.78 \pm 0.25 \mathrm{ab}$ & $9.84 \pm 0.30 \mathrm{c}$ & $7.63 \pm 0.01 \mathrm{c}$ & $23.51 \pm 0.35 \mathrm{c}$ & $1.53 \pm 0.05 \mathrm{abc}$ & $0.82 \pm 0.01 \mathrm{~d}$ & $19.36 \pm 0.86 \mathrm{~cd}$ & $203.17 \pm 2.29 c$ & $08 \pm 0.58 b$ & $15.67 \pm 1.20 \mathrm{bc}$ & $153.33 \pm 16.83 \mathrm{abc}$ \\
\hline S4 & $23.84 \pm 0.34 \mathrm{e}$ & $62.53 \pm 0.24 \mathrm{ab}$ & $13.63 \pm 0.37 \mathrm{a}$ & $7.38 \pm 0.02 \mathrm{~d}$ & $4.87 \pm 0.45 \mathrm{~g}$ & $1.17 \pm 0.02 \mathrm{c}$ & $1.18 \pm 0.03 \mathrm{c}$ & $18.60 \pm 0.22 \mathrm{~d}$ & $177.15 \pm 0.46 \mathrm{e}$ & $12 \pm 1.15 \mathrm{ab}$ & $12.67 \pm 0.33 \mathrm{~cd}$ & $102.67 \pm 18.81 \mathrm{bcd}$ \\
\hline S5 & $26.185 \pm 0.06 \mathrm{~b}$ & $64.09 \pm 0.22 \mathrm{ab}$ & $9.73 \pm 0.19 \mathrm{c}$ & $7.24 \pm 0.03 \mathrm{e}$ & $23.62 \pm 0.65 b$ & $1.39 \pm 0.03 \mathrm{abc}$ & $1.46 \pm 0.03 a$ & $20.44 \pm 0.47 \mathrm{bcd}$ & $188.69 \pm 0.47 \mathrm{~d}$ & $6.67 \pm 2.73 \mathrm{~b}$ & $8 \pm 0.58 \mathrm{~cd}$ & $72 \pm 10.15 \mathrm{~cd}$ \\
\hline S6 & $23.49 \pm 0.31 \mathrm{e}$ & $63.30 \pm 0.518 \mathrm{ab}$ & $13.13 \pm 0.82 \mathrm{a}$ & $7.27 \pm 0.00 \mathrm{e}$ & $19.92 \pm 0.57 d$ & $1.73 \pm 0.13 a$ & $1.23 \pm 0.02 \mathrm{bc}$ & $21.89 \pm 0.26 \mathrm{~b}$ & $202.16 \pm 2.59 c$ & $06 \pm 1.53 \mathrm{~b}$ & $5 \pm 0.59 d$ & $150.67 \pm 10.15 \mathrm{abc}$ \\
\hline S7 & $36.02 \pm 0.10 \mathrm{a}$ & $53.82 \pm 0.32 \mathrm{c}$ & $10.16 \pm 0.24 \mathrm{c}$ & $7.05 \pm 0.01 \mathrm{f}$ & $15.16 \pm 0.43 \mathrm{e}$ & $1.31 \pm 0.14 \mathrm{bc}$ & $0.83 \pm 0.01 \mathrm{~d}$ & $25.08 \pm 0.23 a$ & $251.80 \pm 0.71 \mathrm{a}$ & $7.33 \pm 2.85 \mathrm{~b}$ & $26.33 \pm 0.38 \mathrm{a}$ & $228 \pm 38.57 a$ \\
\hline S8 & $24.58 \pm 0.22 \mathrm{~d}$ & $64.37 \pm 0.21 \mathrm{a}$ & $11.06+0.24 \mathrm{bc}$ & $7.20 \pm 0.05 \mathrm{e}$ & $25.95 \pm 0.63 a$ & $1.34 \pm 0.07 \mathrm{abc}$ & $0.83 \pm 0.03 \mathrm{~d}$ & $20.04 \pm 0.21 \mathrm{bcd}$ & $177.18 \pm 0.48 \mathrm{e}$ & $8.67 \pm 1.20 \mathrm{~b}$ & $23 \pm 2.52 \mathrm{ab}$ & $173.33 \pm 11.85 \mathrm{ab}$ \\
\hline$p$ & $<0.001$ & $<0.000000$ & $<0.000008$ & $<0.001$ & $<0.001$ & $<0.000001$ & $<0.000001$ & $<0.000001$ & $<0.001$ & $<0.001$ & $<0.000001$ & $<0.00004$ \\
\hline
\end{tabular}

Values represent the mean of 4 replicates \pm SE (standard errors);****** indicate that the differences were significant at $\mathrm{P}<0.01$ and $\mathrm{P}<0.001$, respectively. 
According to ANOVA, AUDPC values showed a very highly significant effect depending on the experimental sites ( $p \leq 0.001)$. Data displayed in Figure 1 showed that AUDPC values were significantly higher in S1 (4081) and S2 (4098.5) during the first season (2016), as well as in S5 (3489.5) and S6 (4009.5) during the second season (2017). The lowest values were recorded in S7 (1372) and S8 (1229) within 2016, and in S3 (1372) and S8 (1535) within 2017.

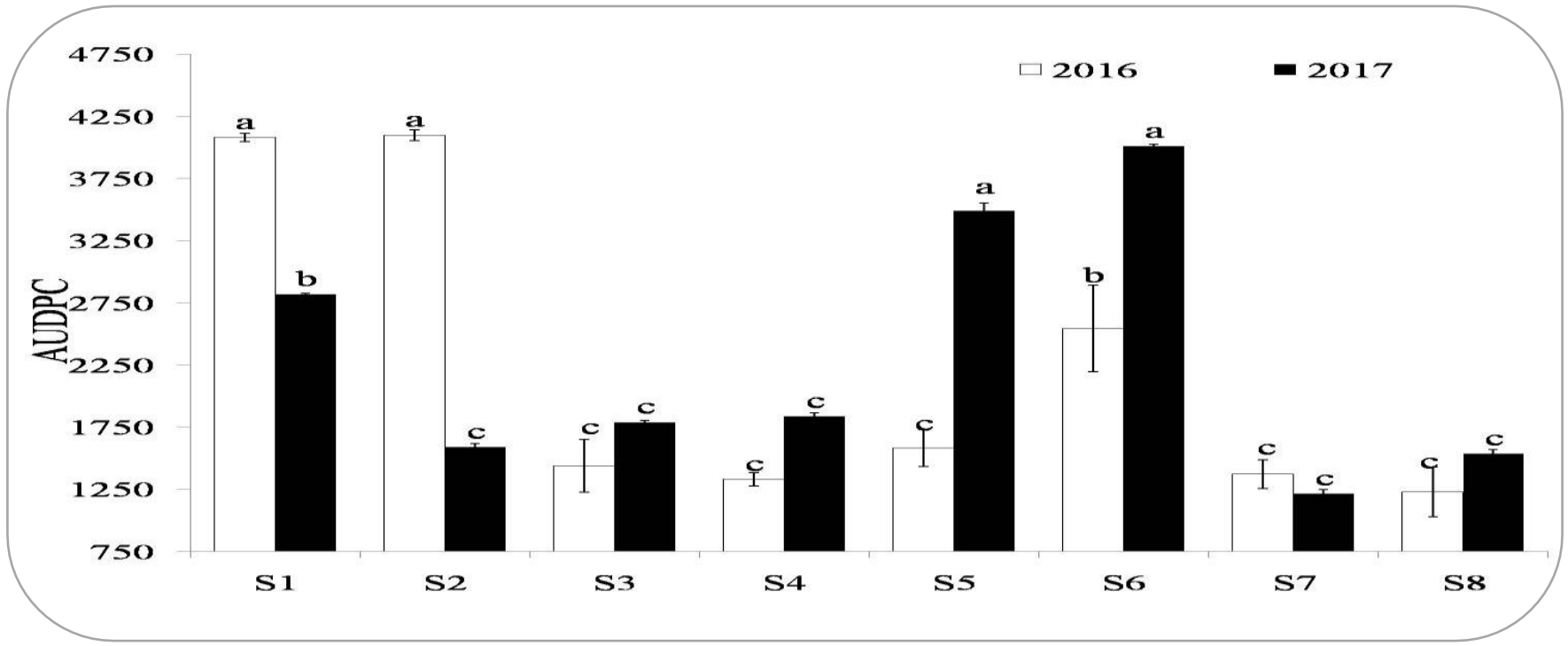

Figure 1. Evaluation of the disease severity (AUDPC) of Fusarium wilt. Values represent the mean of four replicates \pm SE (standard errors). Values of the probability of one-way ANOVA (Site treatment) within a column with different letters denote a significant difference at $\mathrm{P}<0.0001$.

Relationship between wilt disease severity and soil total variance, while in 2017 this accounted for $73.24 \%$ and properties: PCA plots represented the eight experimental sites which were distributed according to the 10 physicochemical and biological soil properties in relation to the disease severity (Figure 2). In 2016, the first and second ordination axis accounted for $81.15 \%$ and $10.19 \%$ of the $11 \%$ of the total variance, respectively. Based on the PCA analysis, AUDPC values were negatively correlated with Olsen-P, nodosity, N-TotalPL, Trichoderma spp and Pseudomonas spp, and positively correlated with ID-Foc, NTotalR, P-TotalpL, SDWt and Yg.
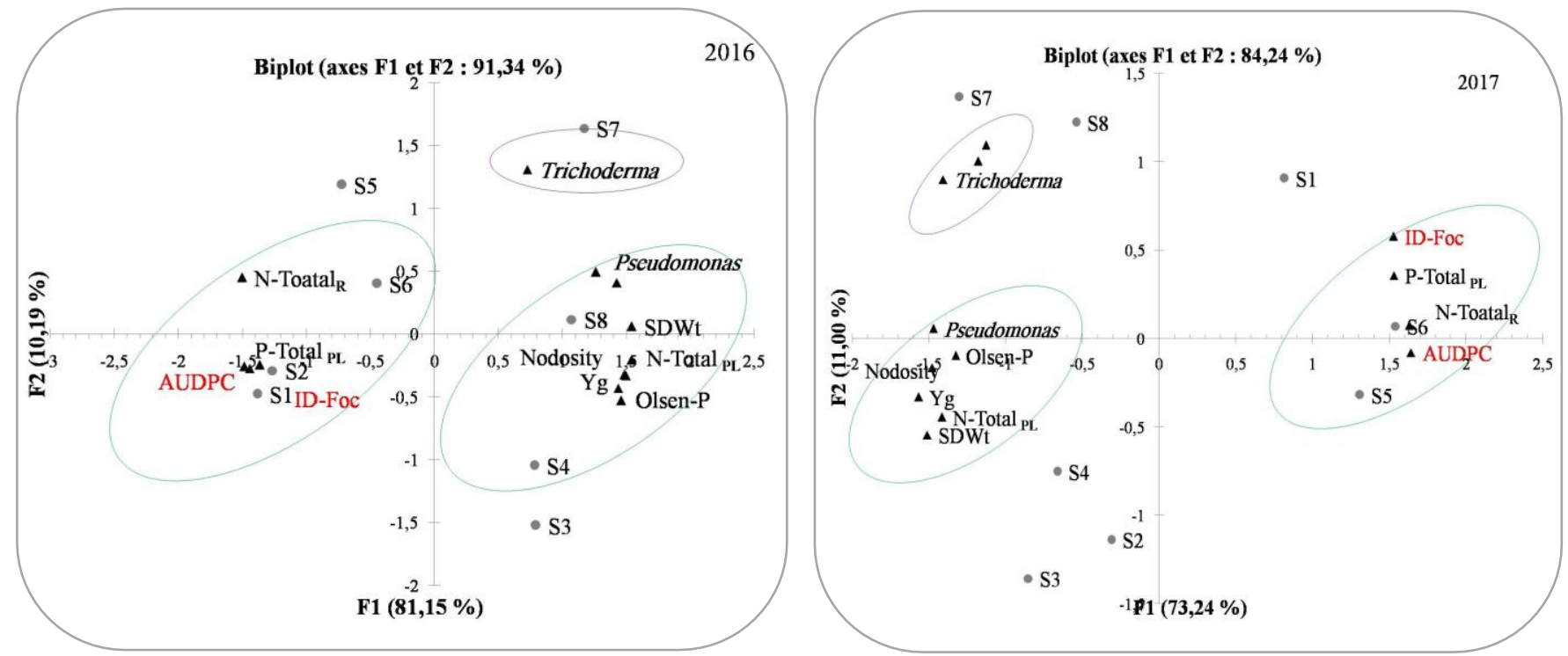

Figure 2. Bioplot of principal component analysis (PCA) of chickpea samples according to physicochemical and biological characteristics and AUDPC. 2016 (F1 accounted for 81.15\% of the variance, and F2 accounted for 11\%), 2017 (F1 accounted for $73.24 \%$ of the variance, and F2 accounted for $10.19 \%$ ). 
Variation of SDWt, $\mathrm{Yg}$, and nodosity in relation to AUDPC: In this study, Yg, SDWt and nodosity varied significantly according to the studied sites $(\mathrm{p}<0.0001)$ (Table 2).

Table 2: Effect of wilt disease on SDWt, Yg, and nodosity in chickpea.

\begin{tabular}{|c|c|c|c|c|c|c|}
\hline \multicolumn{4}{|c|}{2016} & \multicolumn{3}{|c|}{2017} \\
\hline & $\begin{array}{c}\text { SDWt } \\
\left(\text { g plant }^{-1}\right) \\
* * *\end{array}$ & 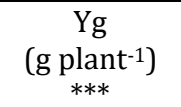 & $\begin{array}{c}\text { Nodosity } \\
\left(\text { mg plant }^{-1}\right) \\
* * *\end{array}$ & $\begin{array}{c}\text { SDWt } \\
\left(\mathrm{g} \mathrm{plant}^{-1}\right) \\
* * *\end{array}$ & $\begin{array}{c}\text { Yg } \\
\left(\text { g plant }^{-1}\right) \\
* * *\end{array}$ & $\begin{array}{c}\text { Nodosity } \\
\left(\text { mg plant }^{-1}\right) \\
* * *\end{array}$ \\
\hline S1 & $0.79 \pm 0.08 c$ & $0.34+0.20 c$ & $1.73 \pm 1.01 \mathrm{~b}$ & $1.35+0.08 \mathrm{bcd}$ & $1.88+0.80 \mathrm{~cd}$ & $24.33 \pm 0.52 c$ \\
\hline $\mathrm{S} 2$ & $0.96 \pm 0.10 \mathrm{c}$ & $0.03+0.02 c$ & $1.50 \pm 0.87 \mathrm{~b}$ & $2.88+0.47 \mathrm{a}$ & $2.33+0.20 b c$ & $30.20 \pm 3.43 b c$ \\
\hline S3 & $2.11 \pm 0.10 \mathrm{ab}$ & $3.38+0.14 a$ & $46.25 \pm 4.93 a$ & $2.91+0.39 a$ & $4.95+0.71 \mathrm{a}$ & $159.61 \pm 2.99 a$ \\
\hline S4 & $1.94 \pm 0.10 \mathrm{ab}$ & $3.28+0.17 \mathrm{ab}$ & $48.40 \pm 2.87 \mathrm{a}$ & $3.26+0.26 a$ & $4.35+0.21 \mathrm{ab}$ & $130.87 \pm 17.71 \mathrm{a}$ \\
\hline S5 & $1.29 \pm 0.47 \mathrm{bc}$ & $0.35+0.21 c$ & $3.83 \pm 2.29 \mathrm{~b}$ & $0.33+0.10 \mathrm{~d}$ & $1.90+0.20 \mathrm{~cd}$ & $0.00+0.00 \mathrm{c}$ \\
\hline S6 & $1.62 \pm 0.20 \mathrm{abc}$ & $0.77+0.22 c$ & $12.93 \pm 3.24 b$ & $0.75+0.14 \mathrm{~cd}$ & $0.13+0.13 c$ & $0.00+0.00 c$ \\
\hline S7 & $2.21+0.01 \mathrm{a}$ & $3.27+0.12 \mathrm{ab}$ & $51.08 \pm 3.08 \mathrm{a}$ & $1.96+0.19 a b c$ & $5.05+0.29 a$ & $152.67 \pm 15.77 a$ \\
\hline S8 & $2.28+0.02 \mathrm{a}$ & $2.61+0.10 \mathrm{~b}$ & $49.80 \pm 3.07 a$ & $2.56+0.33 \mathrm{ab}$ & $3.43+0.41 \mathrm{abc}$ & $56.98 \pm 15.77 \mathrm{~b}$ \\
\hline$p$ & $<0.00001$ & $<0.00001$ & $<0.00001$ & $<0.00001$ & $<0.00001$ & $<0.00001$ \\
\hline
\end{tabular}

Values represent the mean of 4 replicates \pm SE (standard errors); ${ }_{* *}^{* * *}$ indicate that the differences were significant at $\mathrm{P}<0.01$ and $\mathrm{P}<0.001$, respectively.

The results showed that SDWt varied between $0.79 \mathrm{~g}$ and $2.28 \mathrm{~g}$ during 2016. Chickpea cultivars were higher in S8 (2.28 g plant $^{-1}$ ) and S7 (2.21 g plant $^{-1}$ ), when compared to S1 (0.79 g plant $^{-1}$ ) and S2 (0.96 g plant $^{-1}$ ). During 2017, a significant increase in SDWt was observed which ranged from $12.28 \%$ to $70.8 \%$. Yg showed a significant decrease from 2016 to 2017 (from 23.9 to $98.71 \%$ ). The highest Yg was found in S3 (3.38 mg.plant ${ }^{-1}$ ) and S4 (3.28 mg plant ${ }^{-1}$ ) during 2016, whereas, in S8 (5.05 mg plant ${ }^{-1}$ ) and S6 (4.95 mg plant ${ }^{-1}$ ) during 2017. The lowest Yg was found in S1 (0.79 mg plant $^{-1}$ ) and S2 (0.96 mg plant $^{-1}$ ) within 2016, and in S1 (1.88 mg plant $\left.^{-1}\right)$ and S6 (0.13g plant $\left.{ }^{-1}\right)$ within 2017. Nodosity varied between 1.5 to $51.08 \mathrm{mg}$ plant $^{-1}$ during 2016. S1 (1.73 mg plant ${ }^{-1}$ ) and S2 (1.50 mg plant ${ }^{-1}$ ) showed

the lowest values compared to S7 (51.08 mg plant $^{-1}$ ) and S8 (49.80 mg plant ${ }^{-1}$ ). In 2017, a significant increase in nodosity was recorded which evolved from 12.6 to $95.03 \%$. When investigating the relationship between $\mathrm{Yg}$, SDWt, and AUDPC values, significant negative correlations were established (Figure 3a, b, c, d). In terms of $\mathrm{Yg}$, the strong correlation of determination (COD) was recorded in 2017 $\left(r^{2}=0.73\right)$ compared to $2016\left(r^{2}=0.59\right)$, while for SDWt, the COD was higher in $2017\left(r^{2}=0.69\right)$.

Significant negative correlations were also found between nodosity and AUDPC values which are represented by strong COD in $2016\left(r^{2}=0.62\right)$ and $2017\left(r^{2}=0.52\right)$ (Figure. $3 e, f)$. Our results suggest that an increase in nodosity is associated with a decrease in AUDPC levels.
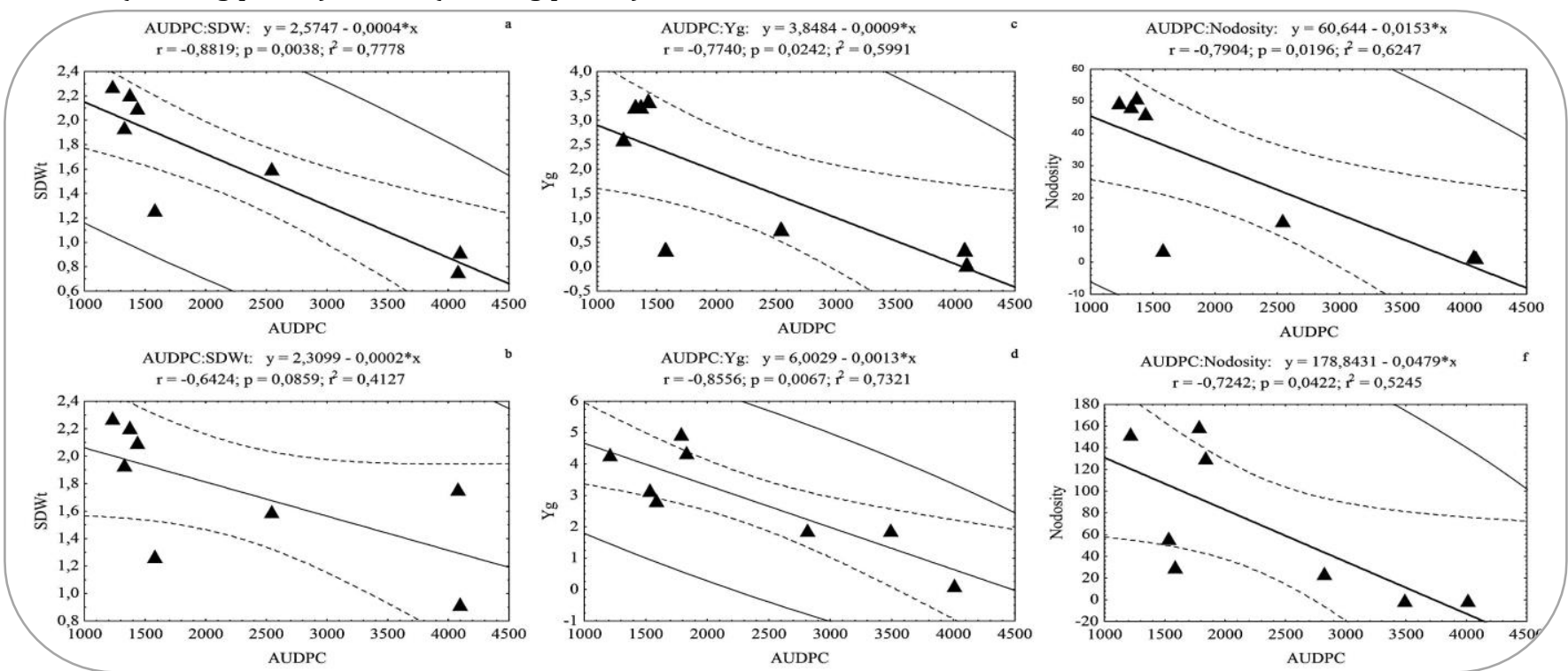

Figure 3. Correlation between SDWt, Yg, nodosity, and AUDPC values. Pearson's linear correlation coefficients $(r)$, coefficients of determination $\left(r^{2}\right)$ and $P$ values are given in each plot. Values are the means of four replicates of plant cultivars collected at the full productive stage. 
Variation of $\mathrm{N}$-Total $\mathrm{R}_{\mathrm{R}} \mathrm{N}$-Total PL $_{\text {in }}$ relation to AUDPC: The concentration of $\mathrm{N}-\mathrm{Total}_{\mathrm{R}}$ and $\mathrm{N}$-Total $\mathrm{PL}$ were significantly affected by site locality $(\mathrm{p}<0.05)$ (Figure $4 \mathrm{a}$, b). In addition, a very important variability was observed among the studied sites according to the season of study.

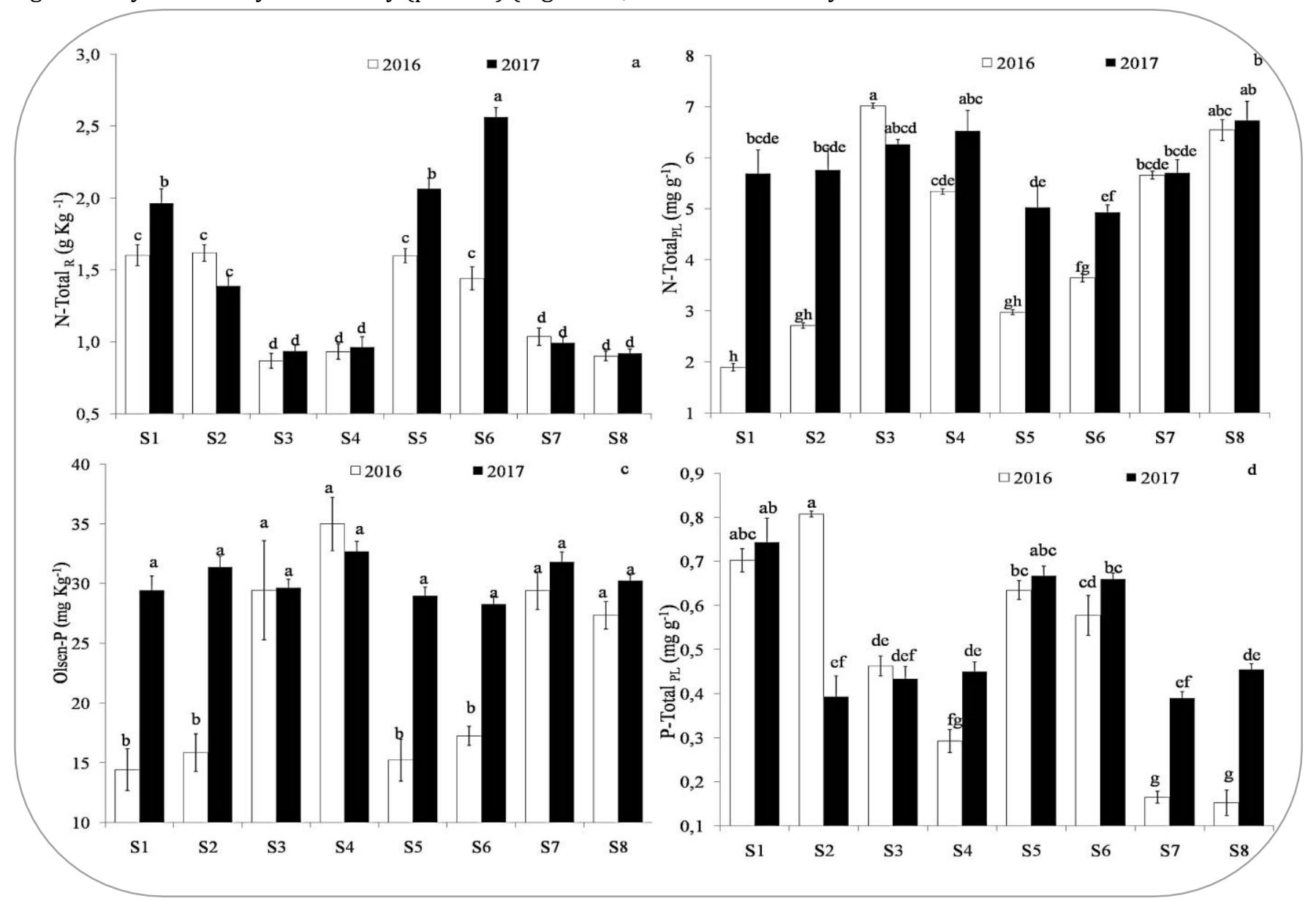

Figure 4. Variation of N-Total $(\mathrm{a}), \mathrm{N}-\mathrm{Total}_{\mathrm{PL}}(\mathrm{b})$, Olsen-P (c), and P-TotalPL (d) in rhizosphere and shoots of chickpea. Values correspond to the mean calculated of five replicates. Letters show significant differences between cropping systems $(\mathrm{P}<0.05)$.

A clear increase of $\mathrm{N}-\mathrm{Total}_{\mathrm{R}}$ was observed in the majority of the studied sites with levels ranging from 5.57 to $28.82 \%$ during 2016. An exception was noticed for S4 with $20.88 \%$ of $\mathrm{N}-$ Total $_{\mathrm{R}}$ decrease. As well, a significant

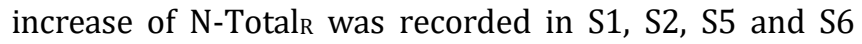
during 2017.

Figure $4 \mathrm{~b}$ showed a significant variability of N-TotalpL plants uptake between the different sites. $\mathrm{N}$-TotalpL was found to be highest in S3 (7.02 mg plant ${ }^{-1}$ ) and S8 (6.54 mg.plant ${ }^{-1}$ ), and very low in S1 and S2 during 2016. The levels of N-Total $\mathrm{PL}$ uptake significantly increased in plants from S1, S2, S6, and S7 during 2017 to reach 52.9\%.

A positive relationship was found between $\mathrm{N}-\mathrm{Total}_{\mathrm{R}}$ and AUDPC with higher COD in $2017\left(r^{2}=0.89\right)$ (Figure 5a, b). However, AUDPC was negatively correlated with $\mathrm{N}$ -

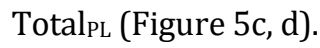

Variation in Olsen-P and $P$-Total $P L$ in relation to AUDPC: According to the ANOVA, the studied sites showed a significantly variation of Olsen-P concentration within the soils during the two years of experimentation ( $\mathrm{p} \leq 0.001$ ) (Figure 4c, d). A significant increase in Olsen-P was found in S3, S4, S7 and S8 with values ranging from 14.69 to $46.82 \%$ during 2016, unlike S1, S2, S5 and S6 which showed a significant decrease in Olsen-P (from 16.98 to $31.5 \%$ ). During 2017, a clear increase of Olsen-P was noticed in the majority of the studied sites with values ranging from 4 to $35.97 \%$.

Regarding P-Total $\mathrm{PL}$, the results showed also an increase in terms of P-Totalp plants uptake in the different sites during 2017. The highest concentrations of P-Total $\mathrm{PL}$ uptake were recorded in 
chickpea cultivars from S1 (0.7 mg plant $\left.{ }^{-1}\right)$ and S2 (0.81 mg plant ${ }^{-1}$ ) during 2016, and in shoot chickpeas from S1 (0.74 mg plant $\left.{ }^{-1}\right)$ and S6 (0.67 mg plant $^{-1}$ ) during 2017. The lowest levels of P-Total $\mathrm{PL}$ were found in shoot chickpeas from S7 and S8 during 2016 as well as S3 and S7 during 2017.
As such, in 2017 a negative relationship was found between AUDPC and Olsen-P values (Figure $5 \mathrm{e}, \mathrm{f}$ ). Here, COD was higher $\left(r^{2}=0.62\right)$. In contrast, a significant positive correlation was observed between P-TotalpL and AUDPC values with a higher $\operatorname{COD}\left(r^{2}=0.76\right)$ (Figure $5 \mathrm{~g}, \mathrm{~h}$ ).

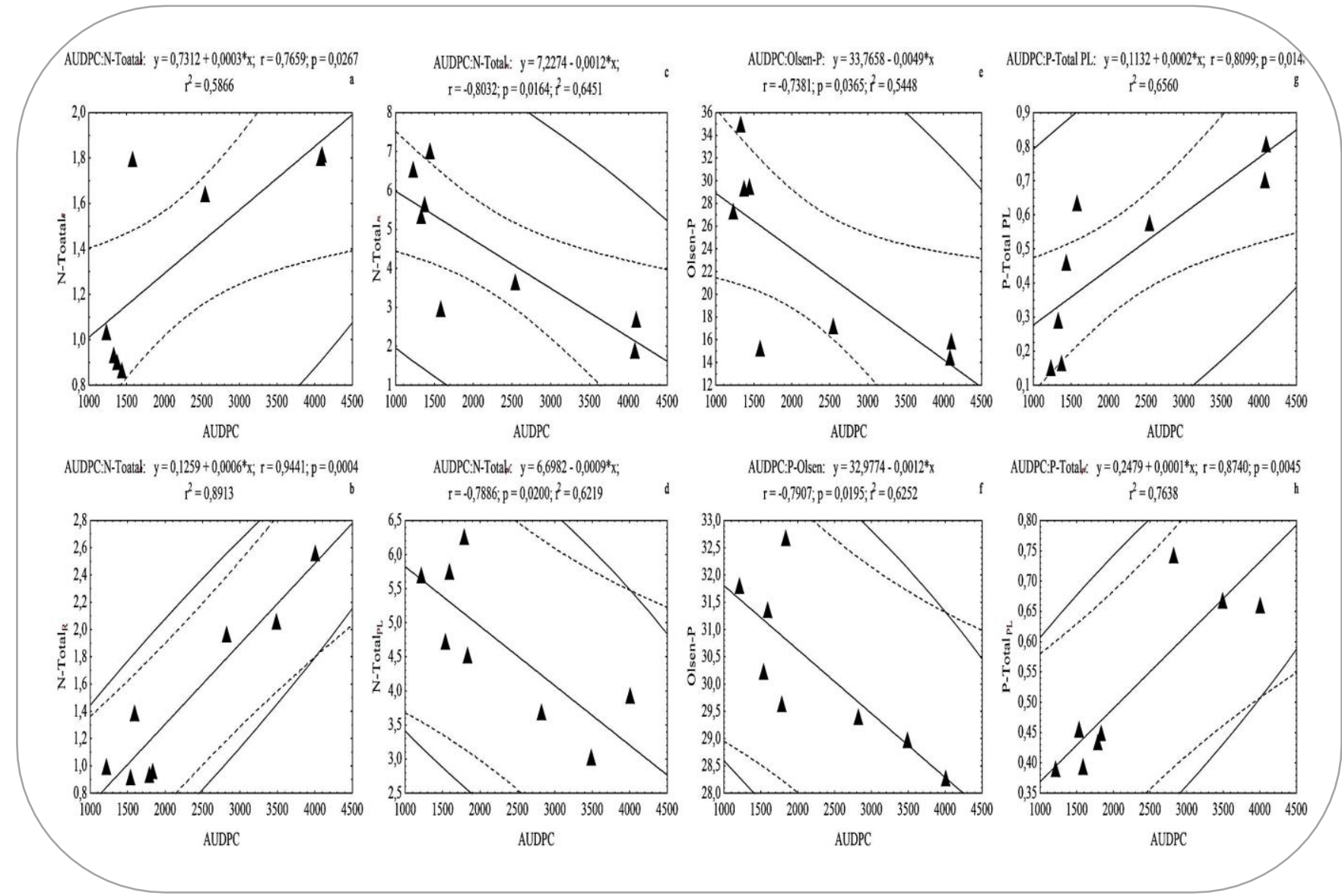

Figure 5. Correlation between $\mathrm{N}-$ Total $_{\mathrm{R}}$, Olsen-P, N-Total $\mathrm{PL}, \mathrm{P}-\mathrm{Total}_{\mathrm{PL}}$, and AUDPC. Values are the means of four replicates at the full productive stage. Pearson's linear correlation coefficients $(r)$, coefficients of determination $\left(r^{2}\right)$ and $\mathrm{P}$ values are given in each plot.

Analysis of correlations between Olsen-P, NTotal $_{R}$, and nodosity: Obtained results showed a negative correlation between $\mathrm{N}$-Total $\mathrm{R}_{\mathrm{R}}$ and Olsen-P with a higher COD in 2016 compared to 2017. Nodosity was also negatively correlated with $\mathrm{N}-$ Total $_{\mathrm{R}}$ during the two years of study and positively correlated with Olsen-P.

Variation of microbial communities and its relation to AUDPC: Figure 6 showed a significant increase in ID-Foc, Trichoderma spp, and Pseudomonas spp in all sites during all period of study.

The results showed an increase in ID-Foc with values ranging between 32.29 to $82.69 \%$ during 2016 and between 25 to $81.44 \%$ during 2017. In contrast, a decrease in ID-Foc was recorded in S1 and S2 with an average of 33.72 and $38.8 \%$ in 2017, respectively.

A significant higher increase in Trichoderma spp levels in the different sites was observed in 2017 (73.93 to $89.82 \%$ ) compared to 2016 (31.42 to $48.27 \%)$.

In the rhizosphere, Pseudomonas spp significantly increased in the different sites during all period of study. In 2016, the highest levels of Pseudomonas spp were found in S7 and S8 which correspond to 26.09 and $21.69 \%$ of total increase, respectively, and up to 40.52 and $53.62 \%$, in S1 and S3 in 2017, respectively. Whereas S5 and S6 showed a decrease of 31.94 and $57.96 \%$ of Pseudomonas spp in 2017, respectively. 


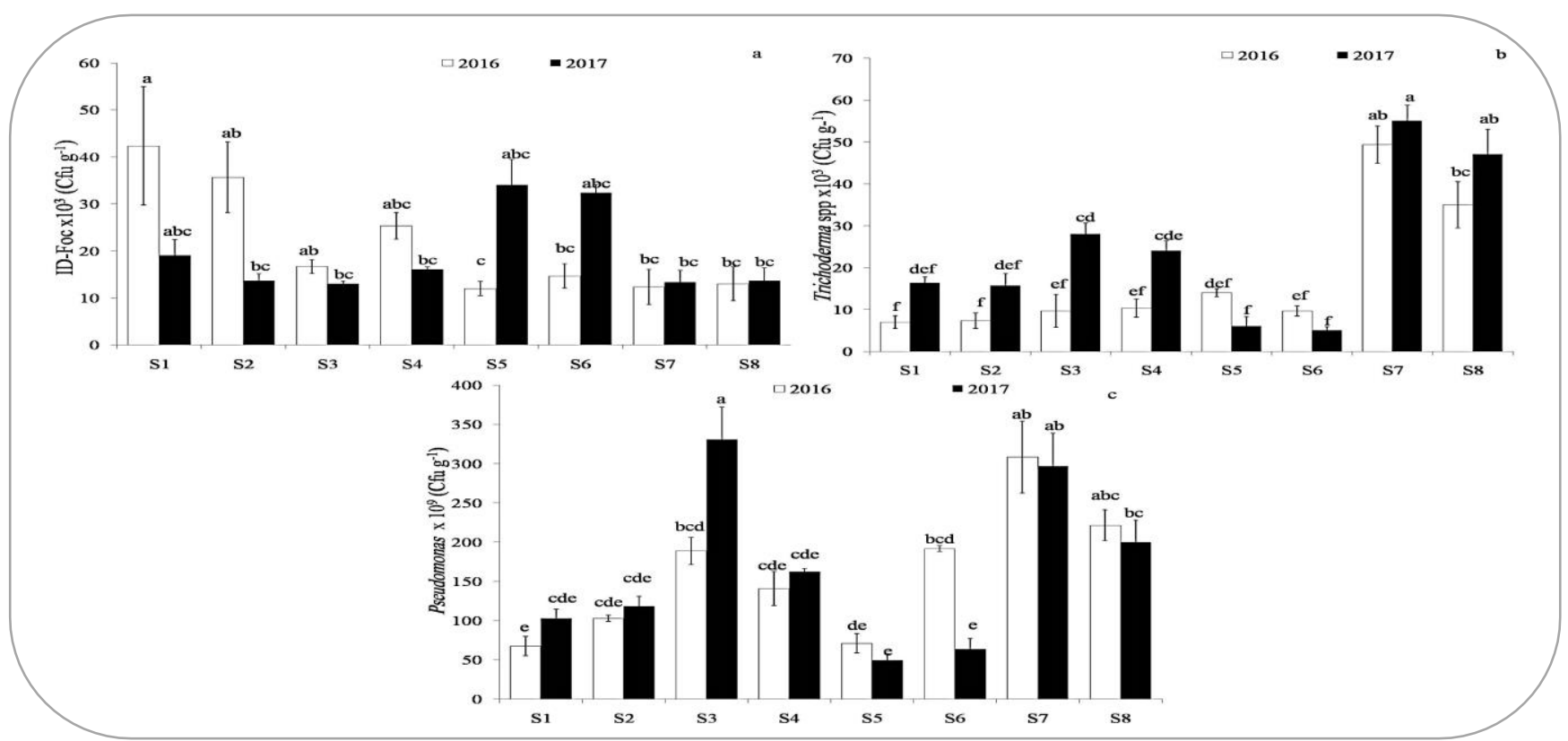

Figure 6. Variation of ID-Foc (a), Trichoderma spp (b) and Pseudomonas spp (c) in the rhizosphere of chickpea. Values correspond to the mean calculated with five replicates. Letters show significant differences between cropping systems $(\mathrm{P}<0.05)$

A positive correlation was found between ID-Foc and AUDPC (Figure 7a, b). The strong COD is observed in $2016\left(r^{2}=0.81\right)$. In contrary, a negative correlation was found between Trichoderma spp, Pseudomonas spp and AUDPC in 2017 (Figure 7c, d). This could be explained by the significant decrease of disease with the increase in Trichoderma spp and

\section{Pseudomonas spp.}

Pseudomonas spp was found to be negatively correlated with ID-Foc during the two years of study (Figure 7e, f); however, it is not correlated with Trichoderma spp. The obtained results also showed positive correlations between Pseudomonas spp and nodosity.

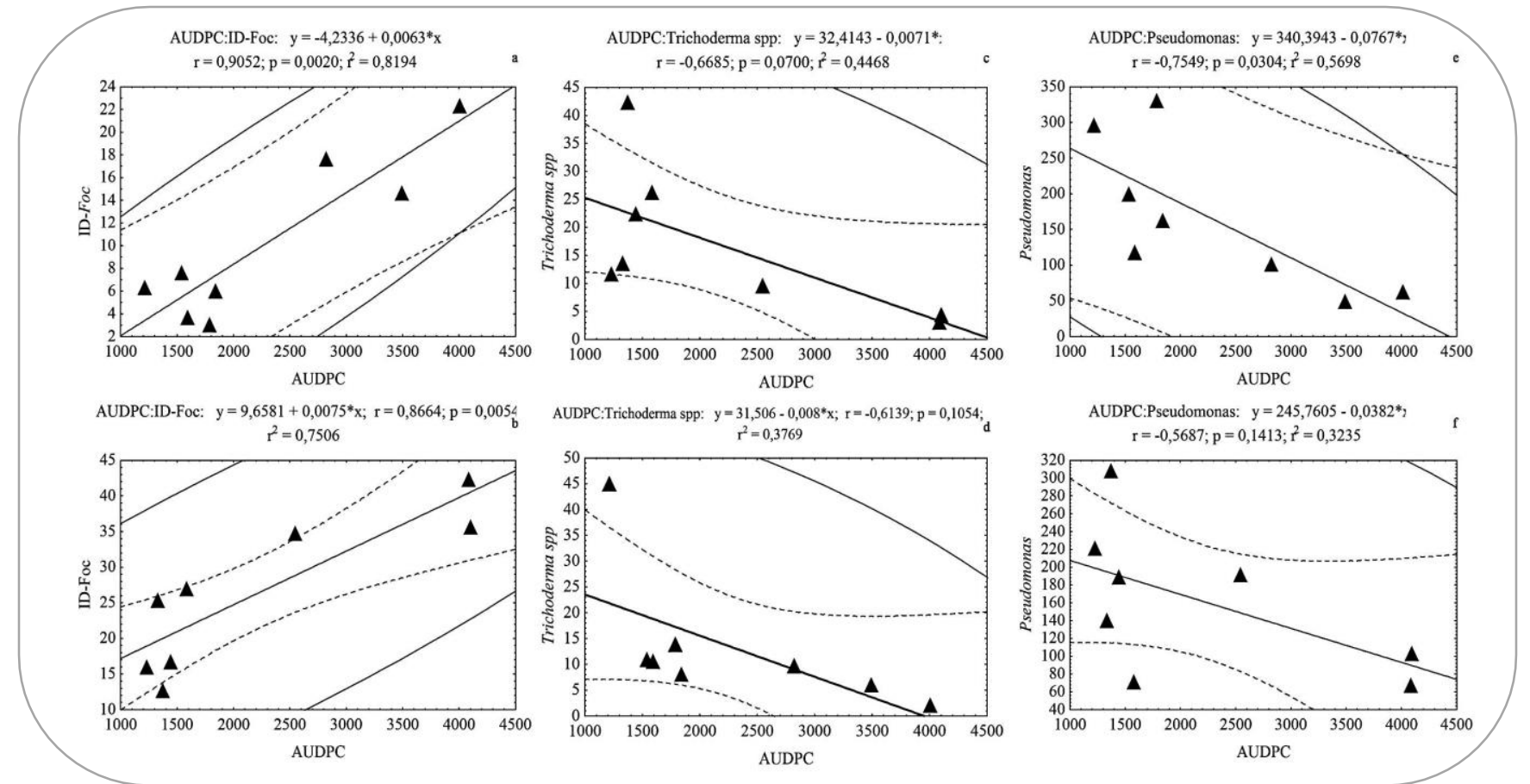

Figure 7. Correlation between ID-Foc, Trichoderma spp, Pseudomonas spp and AUDPC. Pearson's linear correlation coefficients $(r)$, coefficients of determination $\left(r^{2}\right)$ and $P$ values are given in each plot. Values are the means of four replicates collected at the full productive stage. 
Effect of Olsen-P and $\mathrm{N}$-Total $\mathrm{R}_{\mathrm{R}}$ on variations of microbial communities: Pearson correlation analysis showed significant positive correlations between $\mathrm{N}$ Total $_{R}$ and ID-Foc with a higher COD in $2017\left(r^{2}=0.84\right)$. Whereas, significant negative correlations were recorded between ID-Foc and Olsen-P. The data also revealed a negative correlation between ID-Foc and nodosity with a high COD in $2016\left(r^{2}=0.75\right)$ than in 2017 $\left(r^{2}=0.51\right)$. In addition, a negative correlation between $\mathrm{N}$ Total $_{\mathrm{R}}$ and Trichoderma spp $\left(r^{2}=0.61\right)$ was recorded during 2017. These two biological factors were found to be uncorrelated in 2016.

\section{DISCUSSION}

Most of the studies regarding the epidemiology of wilt disease of chickpea have been restricted to controlled conditions with short research periods rather than under natural conditions. However, it is well known that controlled media do not represent the natural conditions that prevail in the rhizosphere of crops (Musyoki et al., 2016). Therefore, this study was conducted in greenhouse experiments during two cropping seasons in eight infested natural's soil for a better understanding of some combined interactions between Fusarium oxysporum population, soil diversity of microorganism (Rhizobia, Pseudomonas spp, and Trichoderma spp) in relation to nutrient elements, especially $\mathrm{N}$ and $\mathrm{P}$ and their combined effect on the severity of vascular wilt disease in chickpea.

A great variability in terms of physicochemical and biological properties was observed in the experimental sites. The results showed a real diverse spatial organization of microbial communities within chickpea rhizosphere in relation to nutrients. Accordingly, chickpea rhizosphere showed specific temporal changes, and dynamic of mineral elements and microorganisms affected either positively or negatively the severity of the disease.

During the experiment, atypical symptoms were observed. It consists of late yellowing, severe defoliation, low flowering and low seed yield. AUDPC values varied significantly according to the geographical origin of soil during the two seasons. AUDPC values were very high in 2016 especially in S1 (4081) and S2 (4098.5) compared to 2017, where the highest values were recorded in S5 (3489.5) and S6 (4009.5). The results showed significant differences in terms of DWSt and Yg among different sites. These results could be attributed to the variations in soil properties and the differences recorded in the disease severity. This study showed a negative effect of AUDPC values on DWSt and Yg. This is in accordance with previous research reporting a significant decrease of chickpea yields under advanced severity of vascular wilt (Jimenez-Diaz et al., 2015).

A large variation of the population size of ID-Foc and disease levels was found within the studied large geographical area which means that physicochemical and biological proprieties of soil affected significantly AUDPC values. We can assume that there is a very complex interaction between physicochemical and biological properties of soil and disease severity. This finding is mainly confirmed by correlation analysis which demonstrates that $\mathrm{N}$-Total $\mathrm{R}$ and P-Total $\mathrm{PL}_{\mathrm{L}}$, ID-Foc were positively correlated with AUDPC, whereas Olsen-P, NTotalPL, Pseudomonas spp and Trichoderma spp were negatively associated with AUDPC.

In natural pathosystem, Fusarium oxysporum inoculum survives in soil as an active form in tissues or in the form of chlamydospores. This increased in the presence of its host plant (Haware et al., 1990). A same outcomes were observed in the present study, showing a clear increase in ID-Foc in all rhizosphere soils after sowing. Therefore, the increased disease severity was, to some extent, associated with the increase of ID-Foc. This is in accordance with previous findings reporting a significant increase of disease severity with increasing ID-Foc (Shuga et al., 1994).

$\mathrm{N}$-Total $\mathrm{R}_{\mathrm{R}}$ was positively correlated with ID-Foc indicating a positive effect of $\mathrm{N}$ on the Fusarium oxysporum population. This may be due to the favorable conditions of Fusarium oxysporum germination and sporulation, therefore, a significant increase in ID-Foc resulted in an advanced disease severity. This is in agreement with previous study demonstrating that higher $\mathrm{N}$ availability decreased mycelial growth and increased the number of produced conidia (Hoffland et al., 2000). Snoeijers et al., (2000) suggested that high levels of $\mathrm{N}$ could have an impact on plantpathogen interactions by activating virulence factors and enhancing the metabolic adaptation of the pathogen. The positive effect of N-Total $\mathrm{R}_{\mathrm{R}}$ on disease severity could be attributed to changes in soil $\mathrm{pH}$. It has been demonstrated that $\mathrm{N}$ fixation can increase $\mathrm{P}$ availability in the rhizosphere through rhizosphere acidification mechanisms resulting from an increase in $\mathrm{H}^{+}$protons by nodulated roots, organic acids or acid phosphatases (Latati et al., 2014).

Our results corroborate previous findings reporting a significant increase of disease severity in association to $\mathrm{N}$ availability in the rhizosphere (Shuga et al., 1994; Rao and Krishnappa 1996). These authors reported that increasing $\mathrm{N}$ played a determining role in vascular wilt in chickpea. As 
well, high $\mathrm{N}$ availability promoted disease and contributed to the increase in the incidence and severity of the disease. In the present study, a significant decrease of AUDPC was associated with a high N-TotalpL plant uptake. Also, increased N-TotalpL was positively associated to nodosity. It has been reported that an increase in $\mathrm{N}$ source induced an accumulation of amino acids, which in turn can affect the activation of plant defense mechanisms (Rojas et al., 2014). However, Dutta et al., (2008) showed that the intensity of the disease was significantly increased with increasing $\mathrm{N}$ content in plant tissues grown in Fusarium udum infested soils.

The results showed positive effects of $\mathrm{N}-\mathrm{Total}_{\mathrm{R}}$ on wilt disease severity, whereas it is negatively correlated with nodosity. The decreased in N-Total, to some extent, is related to the stimulation of efficiency in the rhizobial symbiosis. Previous research reports have mentioned the effect of N-Total in decreasing nodule growth (Alkama et al., 2009). In the other hand, the significant relationship among nodosity and Olsen-P in the rhizosphere of chickpea induced a positive effect of nodule growth. This is in accordance with the previous findings of Betencourt et al., (2012). Similarly, a study by Korir et al., (2017) showed that PGPR possesses the ability of phosphate solubilization improvement by increasing $\mathrm{P}$ content in the soil and enhancing nodulation and $\mathrm{N}$ fixation in the common bean. In addition, to their useful $\mathrm{N}_{2}$-fixing activity with legumes, rhizobia can improve plant $\mathrm{P}$ nutrition by mobilizing inorganic and organic P (Alikhani et al., 2006). Also, in chickpea rhizosphere, increased Olsen-P was shown to be linked to the decrease of disease severity, probably, through the inhibition of chlamydospores germination and Fusarium oxysporum sporulation. This is in line with the results of the present study showing a clear decreasing of ID-Foc under strong $\mathrm{P}$ availability. Rao and Krishnappa, (1996) suggested the association of P with Foc-chickpea interaction and noted a negative correlation between outbreaks caused by Fusarium oxysporum and P content of the soil. Prabhu et al., (2007) reported that improved plant growth through $\mathrm{P}$ nutrition allows the plant to "escape" from attack by fungal pathogens in the soil.

Disease severity was associated with an increase of PTotalpL plant uptake. This could be due to the energy balance after infection. In this regard, Bolton, (2009) reported that the complexity of plant defense responses required an abundant supply of energy, mainly derived from primary metabolic processes. At the same time, these metabolic changes caused by $\mathrm{P}$, may be a general feature of plant-pathogen interactions that therefore affect both the immune system of plants, through the formation and accumulation of secondary metabolites.

In soil-plant-pathogen interactions, microbial communities are responsible for the biological processes that influence the occurrence of plant diseases (Wallenstein, 2017). Microbiological analysis of the rhizospheric soils of the different studied sites showed a positive effect between Rhizobia and Pseudomonas spp population in decreasing disease levels. It is worth noting that the increase in production and yield of chickpea, associated with the improvement of the nutritional quality of the plant, is due to the biological amendment of $\mathrm{N}$ and the bioavailability of Olsen-P.

A significant decrease in disease severity associated with nodosity and elevated Pseudomonas spp was noticed. IDFoc was negatively correlated with high levels of nodosity and Pseudomonas spp. This is in accordance with previous findings reporting that Pseudomonas spp caused a significant decrease in fungal mycelium density and number of macroconidia of Fusarium culmorum population (Strunnikova et al., 2015). Pseudomonas spp has frequently been reported to be responsible for the natural suppression of Fusarium wilt disease (Mazzola, 2002). This process is associated to several mechanisms which include volatile compounds by siderophore production, antibiotics, chitinases, $\beta 1,3$-glucanases and cyanides, asymbiotic nitrogen fixation and solubilization of mineral and other nutrients (Narendra et al., 2015).

In this study negative relationships between ID-Foc, AUDPC values and Trichoderma spp were found, which confirms that Trichoderma species contribute in the process of natural wilt disease management. These species were commonly isolated from the rhizosphere of chickpea and the level of population in the soil is necessary for the control of the disease (Sumeet and Mukerji, 2000). In this respect, Trichoderma spp species probably limit sporulation and Fusarium oxysporum mycelial growth via competition for nutrients and antifungal compounds production. In addition, Dubey et al., (2007) reported that Trichoderma spp contributes to Fusarium oxysporum suppression through a variety of mechanisms such as hyperparasitism, antibiosis, and induction of host resistance. Griffin, (1994) pointed out that mineral nutrition is essential for the growth and the stimulation of fungal secondary metabolites production. This may also explain the positive correlation recorded between N-Total ${ }_{R}$ and Trichoderma spp. 
Results of particular interest from this present study are those concerning the positive correlation between Trichoderma spp and Pseudomonas spp, which were negatively correlated with ID-Foc and AUDPC. Our results demonstrated positive significant correlations between nodosity and Pseudomonas spp. This would undoubtedly be due to the synergistic effect between the population of Pseudomonas spp and Rhizobia. Interestingly, Zaidi et al., (2003) reported that chickpea yield and nutrient uptakes were significantly increased following inoculation of chickpea plants with Rhizobium sp. and Pseudomonas striata solubilizing phosphorus in combination.

\section{CONCLUSION}

This study demonstrates the relationship between soil nutrients and the process of infection of chickpeas by the pathogen. The results in our study are relevant for wilt disease control. Our work demonstrates that chickpea cultivars undergo significant nutrient status changes in relation to AUDPC values. Olsen-P, Trichoderma spp, nodosity, and Pseudomonas were negatively correlated with ID-Foc and consequently reduced severity of disease. $\mathrm{N}$-TotalpL was negatively correlated with AUDPC whereas P-TotalPL was positively correlated with AUDPC. It can be assumed that effective management of available nitrogen and phosphorus and its balance with other nutrients should be considered in an integrated strategy for Fusarium wilt disease management.

\section{ACKNOWLEDGMENTS}

The funding provided by the Algerian Ministry of Higher Education and Scientific Research for this research project (code: D04N01UN340120140012) is gratefully acknowledged. This work was supported by the Laboratory of Characterization and Valorization of Natural Resources, Faculty of Nature and life Sciences, Mohamed El Bachir El Ibrahimi University.

\section{REFERENCES}

Alikhani, H. A., N. Saleh-Rastin and H. Antoun. 2006. Phosphate solubilization activity of rhizobia native to Iranian soils. Plant and Soil, 287: 35-41.

Alkama, N., E. B. Bi Bolou, H. Vailhe, L. Roger, S. M. Ounane and J. J. Drevon. 2009. Genotypic variability in P use efficiency for symbiotic nitrogen fixation is associated with variation of proton efflux in cowpea rhizosphere. Soil Biology and Biochemistry, 41: 1814-1823.

Betencourt, E., M. Duputel, B. Colomb, D. Desclaux and P. Hinsinger. 2012. Intercropping promotes the ability of durum wheat and chickpea to increase rhizosphere phosphorus availability in a low $\mathrm{P}$ soil. Soil Biology and Biochemistry, 46: 181-190.

Bolton, M. D. 2009. Primary Metabolism and Plant Defense-Fuel for the Fire. Molecular Plant-Microbe Interactions, 22: 487-497.

Dubey, S. C., M. Suresh and B. Singh. 2007. Evaluation of Trichoderma species against Fusarium oxysporum f. sp. ciceris for integrated management of chickpea wilt. Biological Control, 40: 118-127.

Dutta, S., A. K. Mishra and B. S. Dileep Kumar. 2008. Induction of systemic resistance against fusarial wilt in pigeon pea through interaction of plant growth promoting rhizobacteria and rhizobia. Soil Biology and Biochemistry, 40: 452-461.

Elmer, W. H. and L. E. Datnoff. 2014. Mineral Nutrition and Suppression of Plant Disease. Encyclopaedia of Agriculture and Food Systems. Elsevier, pp. 231-244.

Gams, W. and J. Bissett. 2002. Morphology and Identification of Trichoderma In: Kubicek, C.P. and Harman, G.E., Eds., Trichoderma and Gliocladium: Basic Biology, Taxonomy and Genetics, Taylor \& Francis Ltd., London.

Ghorbani, R., S. Wilcockson, A. Koocheki and C. Leifert. 2008. Soil management for sustainable crop disease control: A review. Environmental Chemistry Letters, 6: $149-162$.

Griffin, D. H. 1994. Fungal physiology. 2nd Edition. J. Wiley, Sons, New York.

Haware, M., R. Jimenez-Diaz, K. Amin, J. Phillips and H. Halila. 1990. Integrated management of wilt and root rots of chickpea. Chickpea in the Nineties: Proceedings of the second international work shop on chickpea improvement, Patancheru, India: 129137.

Hoffland, E., M. J. Jeger and M. L. van Beusichem. 2000. Effect of nitrogen supply rate on disease resistance in tomato depends on the pathogen. Plant and Soil, 218: 239-247.

Hu, Y. and U. Schmidhalter. 2005. Drought and salinity: A comparison of their effects on mineral nutrition of plants. Journal of Plant Nutrition and Soil Science, 168: 541-549.

Jiménez-Díaz, R. M., P. Castillo, M. d. M. Jiménez-Gasco, B. B. Landa and J. A. Navas-Cortés. 2015. Fusarium wilt of chickpeas: Biology, ecology and management. Crop Protection, 73: 16-27.

Korir, H., N. W. Mungai, M. Thuita, Y. Hamba and C. Masso. 2017. Co-inoculation effect of Rhizobia and plant 
growth promoting Rhizobacteria on common bean growth in a Low Phosphorus Soil. Frontiers in Plant Science, 08.

Lambert, J. 1977. Une technique de minéralisation rapide des végétaux en vue du dosage en série de $\mathrm{N}, \mathrm{P}, \mathrm{K}$, $\mathrm{Na}, \mathrm{Ca}, \mathrm{Mg}, \mathrm{Fe}$, etc. Note Analytique.

Latati, M., D. Blavet, N. Alkama, H. Laoufi, J. J. Drevon, F. Gérard, M. Pansu and S. M. Ounane. 2014. The intercropping cowpea-maize improves soil phosphorus availability and maize yields in an alkaline soil. Plant and Soil, 385: 181-191.

Marschner, H. 1995. Mineral nutrition of higher plants. 2nd edition, Academic press. Inc. London.

Mazzola, M. 2002. Mechanisms of natural soil suppressiveness to soilborne diseases. Antonie van Leeuwenhoek, 81: 557-564.

Messiaen, C. M. and R. Cassini 1968. Recherches sur les Fusarioses. IV. La systématique des Fusarium. Ann. Epiphyt. , 19: 387-45.

Musyoki, M. K., G. Cadisch, J. Zimmermann, H. Wainwright, F. Beed and F. Rasche. 2016. Soil properties, seasonality and crop growth stage exert a stronger effect on rhizosphere prokaryotes than the fungal biocontrol agent Fusarium oxysporum f. sp. strigae. Applied Soil Ecology, 105: 126-136.

Narendra Babu, A., S. Jogaiah, S.-i. Ito, A. Kestur Nagaraj and L.-S. P. Tran. 2015. Improvement of growth, fruit weight and early blight disease protection of tomato plants by rhizosphere bacteria is correlated with their beneficial traits and induced biosynthesis of antioxidant peroxidase and polyphenol oxidase. Plant Science, 231: 62-73.

Navas-Cortés, J. A., B. Hau and R. M. Jiménez-Díaz. 2000. Yield Loss in Chickpeas in Relation to Development of Fusarium Wilt Epidemics. Phytopathology, 90: 1269-1278.

Nene, Y. and M. Haware. 1980. Screening Chickpea for Resistance to Wilt. Plant Disease, 64: 379-380.

Olsen, S. R. 1954. Estimation of available phosphorus in soils by extraction with sodium bicarbonate. United States Department of Agriculture; Washington.

Prabhu, A. S., N.K. Fageria., R.F. Berni and F.A. Rodrigues. 2007. Phosphorus and plant disease. In: Datnoff, L.E., W.H. Elmer and D.M. Huber. (Eds.), Mineral Nutrition and Plant Disease. St. Paul, MN: APS Press, USA. .

Rao, V. and K. Krishnappa. 1996. Relationship between environmental factors and Meloidogyne-Fusarium wilt disease complex in chickpea. Indian Journal of Mycology and Plant Pathology, 26: 221-223.

Rapilly, F. 1968. Les techniques de mycologie en pathologie végétale.

Reddy, M., H. Gridley and H. Kaack. 1980. Major disease problems of chickpea in North Africa. International Chickpea Newsletter.

Rojas, C. M., M. Senthil-Kumar, V. Tzin and K. S. Mysore. 2014. Regulation of primary plant metabolism during plant-pathogen interactions and its contribution to plant defense. Frontiers in Plant Science, 5.

Snoeijers, S. S., A. Pérez-García, M. H. Joosten and P. J. De Wit. 2000. The effect of nitrogen on disease development and gene expression in bacterial and fungal plant pathogens. European Journal of Plant Pathology, 106: 493-506.

Strunnikova, O. K., N. A. Vishnevskaya, A. S. Ruchiy, V. Y. Shakhnazarova, N. I. Vorobyov and V. K. Chebotar. 2015. The influence of soils with different textures on development, colonization capacity and interactions between Fusarium culmorum and Pseudomonas fluorescens in soil and on barley roots. Plant and Soil, 389: 131-144.

Sugha, S., S. Kapoor and B. Singh. 1994. Factors influencing Fusarium wilt of chickpea (Cicer arietinum L.). Indian Journal of Mycology and Plant Pathology (India).

Sumeet and K. G. Mukerji. 2000. Exploitation of Protoplast Fusion Technology in Improving Biocontrol Potential. Biocontrol Potential and its Exploitation in Sustainable Agriculture. Springer US, pp. 39-48.

Trapero Casas, A. and R. M. Jiménez Díaz. 1985. Fungal wilt and root rot diseases of chickpea in Southern Spain.

Valizadeh, G. R., Z. Rengel and A. W. Rate. 2003. Response of wheat genotypes efficient in $\mathrm{P}$ utilisation and genotypes responsive to $\mathrm{P}$ fertilisation to different $\mathrm{P}$ banding depths and watering regimes. Australian Journal of Agricultural Research, 54: 59.

Wallenstein, M. D. 2017. Managing and manipulating the rhizosphere microbiome for plant health: A systems approach. Rhizosphere, 3: 230-232.

Zaidi, A., M. S. Khan and M. Amil. 2003. Interactive effect of rhizotrophic microorganisms on yield and nutrient uptake of chickpea (Cicer arietinum L.). European Journal of Agronomy, 19: 15-21. 